\title{
Structural Characterization of Anticancer Drug Paclitaxel and Its Metabolites Using Ion Mobility Mass Spectrometry and Tandem Mass Spectrometry
}

\author{
Hong Hee Lee, ${ }^{1,2}$ Areum Hong, ${ }^{1}$ Yunju Cho, ${ }^{3}$ Sunghwan Kim, ${ }^{3}$ Won Jong Kim, ${ }^{1,4}$ \\ Hugh I. $\mathrm{Kim}^{2}$ \\ ${ }^{1}$ Department of Chemistry, Pohang University of Science and Technology (POSTECH), Pohang, 790-784, Korea \\ ${ }^{2}$ Department of Chemistry, Korea University, Seoul, 136-713, Korea \\ ${ }^{3}$ Department of Chemistry, Kyungpook National University, Daegu, 702-701, Korea \\ ${ }^{4}$ Center for Self-Assembly and Complexity, and Institute for Basic Science (IBS), Pohang University of Science and Technology \\ (POSTECH), Pohang, 790-784, Korea
}

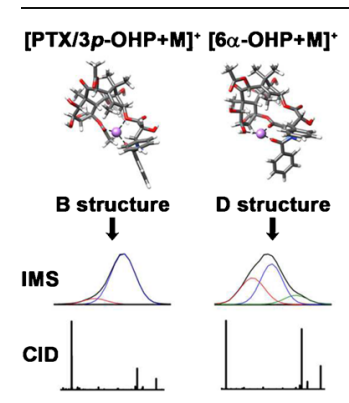

Abstract. Paclitaxel (PTX) is a popular anticancer drug used in the treatment of various types of cancers. PTX is metabolized in the human liver by cytochrome $\mathrm{P} 450$ to two structural isomers, $3^{\prime}$ - $p$-hydroxypaclitaxel (3p-OHP) and $6 \alpha-$ hydroxypaclitaxel (6a-OHP). Analyzing PTX and its two metabolites, $3 p-\mathrm{OHP}$ and $6 \alpha-\mathrm{OHP}$, is crucial for understanding general pharmacokinetics, drug activity, and drug resistance. In this study, electrospray ionization ion mobility mass spectrometry (ESI-IM-MS) and collision induced dissociation (CID) are utilized for the identification and characterization of PTX and its metabolites. Ion mobility distributions of $3 p-\mathrm{OHP}$ and 6a-OHP indicate that hydroxylation of PTX at different sites yields distinct gas phase structures. Addition of monovalent alkali metal and silver metal cations enhances the distinct dissociation patterns of these structural isomers. The differences observed in the CID patterns of metalated PTX and its two metabolites are investigated further by evaluating their gas-phase structures. Density functional theory calculations suggest that the observed structural changes and dissociation pathways are the result of the interactions between the metal cation and the hydroxyl substituents in PTX metabolites.

Keywords: Paclitaxel, 3'-p-Hydroxypaclitaxel, 6a-Hydroxypaclitaxel, Metabolites, Ion mobility mass spectrometry, Collision induced dissociation, Density functional theory, Fragmentation pathway, Alkali metal, Silver, Structural characterization

Received: 3 June 2015/Revised: 15 September 2015/Accepted: 18 September 2015/Published Online: 14 October 2015

\section{Introduction}

$\mathrm{P}$ aclitaxel (PTX, Scheme 1) is a widely used drug in chemotherapy. PTX is prescribed alone or in combination with other anticancer agents for several lung [1], breast [2], ovarian [3], head, and neck cancers [4]. PTX binds to $\beta$-tubulin and arrests the cell cycle in its mitotic phase, the cell cycle that the parent cell divides into two daughter cells by separating duplicated chromosomes and cell nucleus. Complexation of

Electronic supplementary material The online version of this article (doi:10. 1007/s13361-015-1280-1) contains supplementary material, which is available to authorized users.

Correspondence to: Hugh I. Kim; e-mail: hughkim@korea.ac.kr
PTX with $\beta$-tubulin enhances the polymerization of $\beta$ tubulins and stabilizes the microtubules to inhibit treadmilling dynamics, leading to inhibition of cancer cell division and cell apoptosis [5, 6]. However, PTX treatment can fail because of the various drug resistance mechanisms $[6,7]$. The expression of cytochrome P450 (CYP) is one of the factors contributing to the resistance towards PTX [8-10]. The CYP family of enzymes plays a critical role in the phase I of drug metabolism $[11,12]$. Phase I of drug metabolism encompasses enzymemediated modifications involving the addition or removal of small chemical moieties to drugs, such as hydroxylation, oxidation, deamination, and hydrolysis [13]. PTX is predominantly metabolized in the human liver by CYP to two structural isomers, $3^{\prime}$ - $p$-hydroxypaclitaxel (3p-OHP, Scheme 1) and $6 \alpha-$

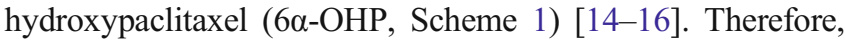




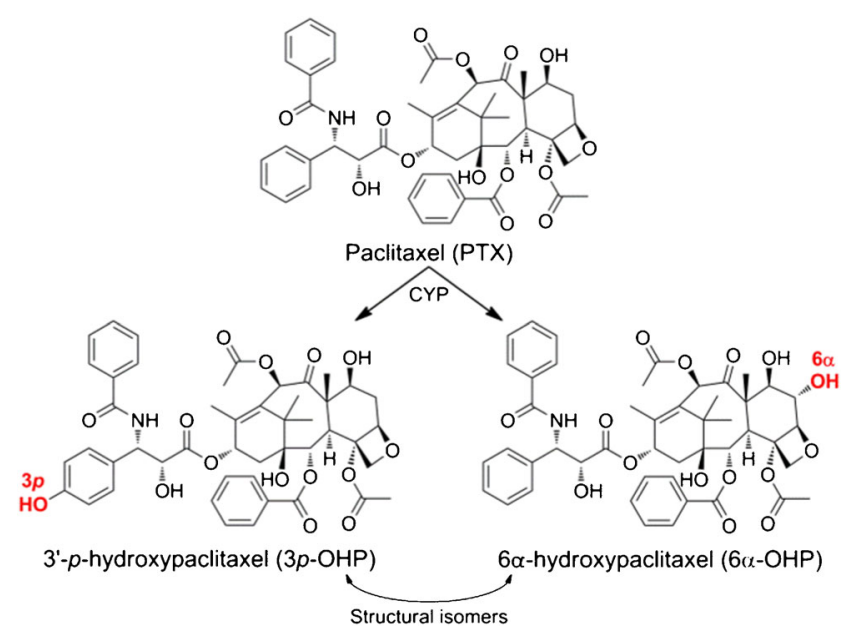

Scheme 1. Structure of PTX, 3p-OHP, and $6 a-\mathrm{OHP}$

monitoring metabolites of PTX resulting from the action of CYP is critical to gain insights into chemotherapeutic drug resistance $[8,9]$ and further pharmacokinetics studies [17, 18]. Several studies have analyzed PTX and its metabolites, $3 p$-OHP and $6 \alpha-\mathrm{OHP}$, in different samples, such as tissue extract, serum, plasma, and urine, using tandem mass spectrometry interfaced with liquid chromatography (LC-MS/MS) $[19,20]$. These studies have shown that $3 p$-OHP and $6 \alpha-\mathrm{OHP}$ can be distinguished by the collision induced dissociation (CID) patterns in their tandem mass spectra. Although metabolite-specific fragments have been identified in previous studies, their CID patterns are yet to be understood in relation to their structural difference in the gas phase.

In the present study, using electrospray ionization ion mobility mass spectrometry (ESI-IM-MS) and low-energy CID, we have characterized PTX and its metabolites on the basis of their gas-phase structural properties. IM-MS has been actively utilized for various applications, including characterization of the structures of small drug-like molecules [21, 22], peptides $[23,24]$, proteins [25], and polymers [26]. Moreover, simultaneous characterization of molecular ions based on their gasphase conformations can provide valuable insights into their potential structural isomers [27-30]. In an IM cell, ions collide with neutral buffer gas and these collisions influence the traveling time of the ions depending on their charge, size, and shape. The traveling time of an ion can be converted into its experimentally determined collision cross section $\left(\Omega_{\mathrm{D} \text {,exp }}\right)$. Insights into the conformations are subsequently gained by comparing the $\Omega_{\mathrm{D} \text {,exp }}$ to the theoretical $\Omega_{\mathrm{D}}\left(\Omega_{\mathrm{D} \text {,theo }}\right)$ of structural models generated by computation.

Introducing metal ions to organic molecules is beneficial for ionizing organic compounds devoid of basic/acidic functional groups. In addition, diverse interactions between different metal cations and ligand molecules allow unique structural rearrangements and dissociation pathways [31,32]. Recent studies demonstrated the effect of alkali metal and silver metal cations to generate different CID patterns [33-35]. In case of alkali metal cations, the ion sizes and binding properties influence the complex structures and CID patterns [33, 36]. In addition, silver metal cation shows specific fragmentation patterns, which is considered to be related to the silver- $\pi$ interaction $[34,35,37]$. We therefore chose proton $\left(\mathrm{H}^{+}\right)$, alkali metal $\left(\mathrm{Li}^{+}\right.$, $\mathrm{Na}^{+}$, and $\left.\mathrm{K}^{+}\right)$, and silver $\left(\mathrm{Ag}^{+}\right)$metal cations to investigate the structural changes and CID patterns of PTX and its two metabolites in the gas phase. Analyses of the results reveal that the conformation and dissociation patterns of PTX and $3 p$-OHP ions bear similarities. However, $6 \alpha-\mathrm{OHP}$ ions show distinct structures and CID patterns compared with those of PTX and $3 p$-OHP. CID of metalated PTX and its metabolites show selective ester bond dissociations. Density functional theory (DFT) calculation is performed to understand the observed structural changes and dissociation pathways of PTX and its metabolites.

\section{Experimental}

\section{Materials}

Paclitaxel (PTX), 3'-p-hydroxypaclitaxel (3p-OHP), and 6 $\alpha$ hydroxypaclitaxel ( $6 \alpha-\mathrm{OHP})$ were purchased from BD Biosciences (San Diego, CA, USA) and used without further purification. Lithium chloride and sodium chloride were purchased from Samchun Pure Chemical (Pyeongtaek, Korea). Potassium chloride from Junsei Chemical (Tokyo, Japan) and silver nitrate from Tokyo Chemical Industry (Tokyo, Japan) were used. HPLC-grade water, ethanol, (J. T. Baker, Phillipsburg, NJ, USA) and formic acid (Sigma-Aldrich, St. Louis, MO, USA) were used. Polyalanine was purchased from Sigma-Aldrich. The final concentration of the analyte (PTX, $3 p$-OHP, and $6 \alpha-$ OHP) was adjusted to $5 \mu \mathrm{M}$. Except for silver nitrate, all the other metal salts were added to be equimolar with the analyte. Silver nitrate concentration was selected to be 10 -fold of paclitaxel and its metabolites to obtain observable signal of complex. All sample solutions were prepared in 50/50 water/ethanol with $0.5 \%$ of formic acid by volume.

\section{Electrospray Ionization Traveling Wave Ion Mobility Mass Spectrometry (ESI-TWIM-MS)}

IM-MS measurements were performed on a Synapt G2 HDMS traveling wave ion mobility orthogonal acceleration time-offlight (Synapt G2 instrument, Waters, Milford, MA, USA) in positive ion mode. Source temperature of $150^{\circ} \mathrm{C}$, capillary voltage of $3.5 \mathrm{kV}$, desolvation temperature of $200^{\circ} \mathrm{C}$, and cone voltage of $40 \mathrm{~V}$ were used as parameters for ESI. The helium cell was set with a flow rate of $180 \mathrm{~mL} / \mathrm{min}$. Nitrogen drift gas was introduced into the IM cell at a $60 \mathrm{~mL} / \mathrm{min}$ of flow rate. Optimized traveling wave height and velocity were $40 \mathrm{~V}$ and $600 \mathrm{~m} / \mathrm{s}$, respectively. For each sample, 120 spectra were obtained and averaged. The arrival times of analyte ions were extracted using MassLynx software (ver. 4.1, Waters, Milford, MA, USA). Multiple peak fitting of IM spectra were performed by Origin 9.0 software (OriginLab, Northampton, MA, USA) with Gaussian function. 


\section{Collision Induced Dissociation (CID)}

Tandem MS experiments of cationized PTX, $3 p$-OHP and $6 \alpha-$ OHP ions were performed on a Thermo Scientific Q-Exactive hybrid quadrupole-Orbitrap mass spectrometer (Q-Orbitrap instrument, Thermo Scientific, San Jose, CA, USA) in positive ion mode. Samples were injected with a syringe pump at a flow rate of $5 \mu \mathrm{L} / \mathrm{min}$, and the electrospray voltage and capillary temperature were set as $3.0 \mathrm{kV}$ and $200^{\circ} \mathrm{C}$, respectively. Spectra of all samples were acquired over 200 scans and averaged, and the peaks were analyzed using Thermo Xcalibur 2.1 software (Thermo Scientific). The $20 \%$ of the normalized collision energy was applied to all analyte ions. Additional tandem MS experiments were performed on the Synapt G2 HDMS instrument along with the IM separation in positive ion mode at the trap (CID-IM-MS) and the transfer cell (IM-CIDMS), which were placed before and after the IM cell, respectively. Spectra of all samples were acquired over 200 scans and averaged, and the peaks were analyzed using MassLynx software (ver. 4.1, Waters, Milford, MA, USA). Forty eV of collision energy was applied to all analyte ions, and the other parameters were the same to the IM-MS experiments without tandem MS.

\section{Collision Cross Sections $\left(\Omega_{D}\right)$}

The experimental collision cross sections ( $\left.\Omega_{\mathrm{D} \text {,exp }}\right)$ of cationized PTX, $3 p$-OHP, or $6 \alpha$-OHP were obtained using a calibration method previously reported by Thalassinos et al. [38], based on the published collision cross sections in helium drift gas $\left(\Omega_{\mathrm{He}}\right)$. Using polyalanine, a calibration curve was plotted by fitting previously published $\Omega_{\mathrm{D}}$ values to the drift time of ions [39]. The arrival times of ions were corrected for mass-independent and mass-dependent times to obtain effective drift times. Massindependent time corrections were made for the times required to traverse the transfer and mobility cells, and the massdependent time corrections were made for the TOF of each ions. Then, the effective drift times were plotted against the published $\Omega_{\mathrm{D}}$ values in power relationship to gain time- $\Omega_{\mathrm{D} \text {,exp }}$ relationship. $\Omega_{\mathrm{D} \text {,theo }}$ values were calculated with the hard sphere projection approximation model in the Sigma program [40], which was successful in calculating $\Omega_{\mathrm{D} \text {,theo }}$ of molecules with heteroatomic composition [41]. For lithium and silver, whose parameters were absent in the Sigma and Mobcal program, their van der Waals radii were assumed to be their gasphase hard sphere radii [42] in agreement with the hard sphere descriptions of the Sigma program.

\section{Density Functional Theory (DFT) Calculations}

The gas-phase structures and energetics of cationized PTX, $3 p$ $\mathrm{OHP}$, and $6 \alpha-\mathrm{OHP}$ were determined by DFT calculations using the Q-Chem 4.1 computational package (Q-Chem Inc., Pittsburgh, PA, USA). Initial PTX structure was extracted from microtubule bound crystal structure (pdb id: 2HXF) and optimized further at the B3LYP/6-31G(d) level of theory. For the metabolites, hydrogen atoms at the $3 p$ or $6 \alpha$ positions in the optimized PTX structure were replaced with a hydroxyl group to build the initial $3 p$-OHP or $6 \alpha-\mathrm{OHP}$ structure, respectively. Subsequently, the obtained $3 p$-OHP and $6 \alpha$-OHP structures were re-optimized at the B3LYP/6-31G(d) level. Over 20 potential cation binding sites were evaluated. The structures of argentated complexes were optimized with B3LYP/ LANL2DZ-6-31G(d) [43], in which LANL2DZ ECP was used for silver and 6-31G(d) for all other atoms because the parameters for silver atom were not present in the B3LYP/6-31G(d) basis set. Cationized fragments resulting from CID were optimized at the B3LYP/6-31G(d) level. For the argentated fragment ions, B3LYP/LANL2DZ-6-31G(d) level of calculation was used for optimization. Zero-point energy was corrected for all parent molecules and their CID products.

\section{Results and Discussion}

\section{IM Distribution of PTX and Its Metabolites with Various Cations}

PTX and its two hydroxylated metabolites, $3 p$-OHP and $6 \alpha-$ OHP, were evaluated by ESI-IM-MS (Synapt G2 HDMS instrument) with various monovalent cations $\left(\mathrm{H}^{+}, \mathrm{Li}^{+}, \mathrm{Na}^{+}, \mathrm{K}^{+}\right.$, and $\mathrm{Ag}^{+}$). Singly charged protonated or metalated ions were observed in the mass spectra. The mass spectra obtained from ESI-IM-MS were similar to those from the ultrahigh resolution mass spectrometer (Q-Orbitrap instrument), and no dimers or trimers were found, based on the isotope pattern in the both instruments (Supplementary Figure S1).

The IM distributions of PTX and its hydroxylated metabolites were examined to investigate the structural differences induced by cationization. Figure 1a shows the IM spectra of the PTX ions with various cations plotted against the $\Omega_{\mathrm{D} \text {,exp }}$ values. In the gas phase, the protonated PTX ions $\left([\mathrm{PTX}+\mathrm{H}]^{+}\right)$ exist in two conformations, one with a $\Omega_{\mathrm{D}}$ of $204 \AA^{2}$ and the other with $212 \AA^{2}$. It is evident from the IM spectrum that the compact conformer is more favored than the extended one. Lithiated PTX ions ([PTX $\left.+\mathrm{Li}]^{+}\right)$adopt two conformations $\left(\Omega_{\mathrm{D}} \sim 204\right.$ and $\left.211 \AA^{2}\right)$, whereas sodiated PTX ions ([PTX + $\left.\mathrm{Na}]^{+}\right)$assume a single conformation $\left(\Omega_{\mathrm{D}} \sim 211 \AA^{2}\right)$. Potassiated PTX ions $\left([\mathrm{PTX}+\mathrm{K}]^{+}\right)$predominantly exist as the conformer with $\Omega_{\mathrm{D}}$ of $212 \AA^{2}$, with a tailing distribution in higher $\Omega_{\mathrm{D}}$. Argentated PTX ions ([PTX $\left.+\mathrm{Ag}]^{+}\right)$possess a single conformation $\left(\Omega_{\mathrm{D}} \sim 204 \AA^{2}\right)$. In summary, PTX with alkali metal cations predominantly prefer to exist in the conformers with $\Omega_{\mathrm{D}}$ of 211-212 $\AA^{2}$, whereas the argentated PTX ions assume a relatively more compact conformer $\left(\Omega_{\mathrm{D}} \sim 204 \AA^{2}\right)$.

The structural preferences for the cationized $3 p$-OHP are similar to those of PTX. As seen in Figure 1b, the compact conformer $\left(\Omega_{\mathrm{D}} \sim 209 \AA^{2}\right)$ of [3p-OHP $\left.+\mathrm{H}\right]^{+}$is more abundant than the extended conformer $\left(\Omega_{\mathrm{D}} \sim 217 \AA^{2}\right)$. The alkali metalated $3 p$-OHP ions dominantly form conformers with $\Omega_{\mathrm{D}}$ of $216 \AA^{2}$, and the argentated ion forms a conformer with $\Omega_{\mathrm{D}} \sim$ $208 \AA^{2}$. By contrast, IM spectra of $6 \alpha$-OHP ions are distinct from those of PTX and $3 p$-OHP. Although two conformers are also observed for the protonated $6 \alpha-\mathrm{OHP}$ ions $\left([6 \alpha-\mathrm{OHP}+\mathrm{H}]^{+}\right.$, 
(a)

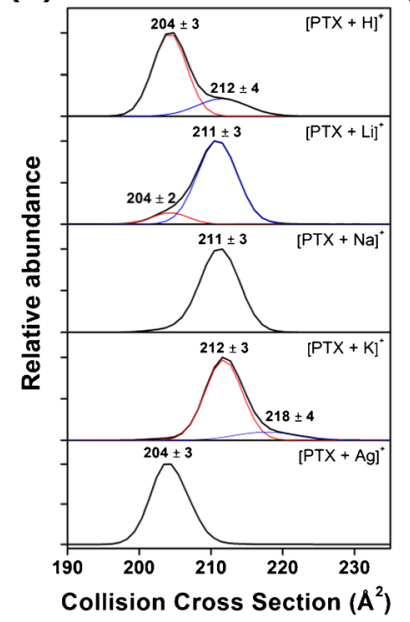

(b)

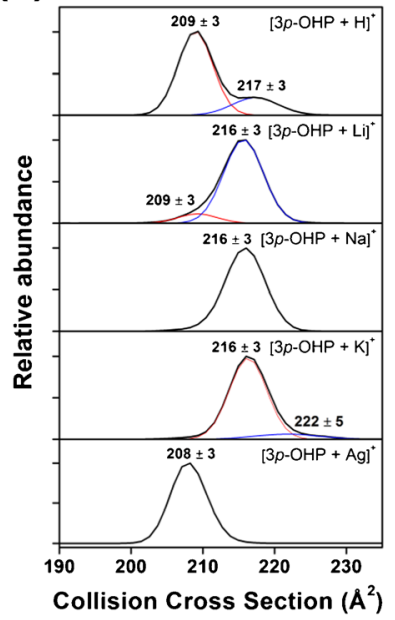

(c)

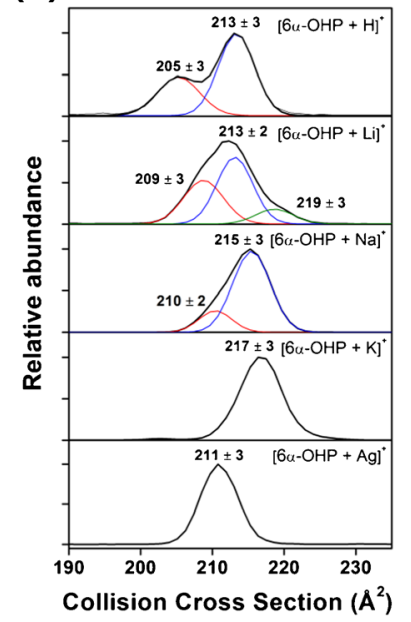

Figure 1. IM spectra of cationized (a) PTX, (b) $3 p-\mathrm{OHP}$, and (c) $6 \mathrm{a}-\mathrm{OHP}$. The data corresponding to $\mathrm{H}^{+}, \mathrm{Li}^{+}, \mathrm{Na}^{+}, \mathrm{K}^{+}$, and $\mathrm{Ag}^{+}$binding ions are displayed sequentially from top to bottom in each panel. $\Omega_{\mathrm{D} \text {,exp }}$ values and their standard deviations $\left(\AA^{2}\right)$ are displayed along with fitted peaks

Figure 1c), the larger conformer $\left(\Omega_{\mathrm{D}} \sim 213 \AA^{2}\right)$ is preferred over the smaller one $\left(\Omega_{\mathrm{D}} \sim 205 \AA^{2}\right)$. The lithiated ions exist in three conformers with $\Omega_{\mathrm{D}}$ of 209,213 , and $219 \AA^{2}$. The sodiated and potassiated $6 \alpha-\mathrm{OHP}$ ions $\left([6 \alpha-\mathrm{OHP}+\mathrm{Na}]^{+}\right.$and $\left.[6 \alpha-\mathrm{OHP}+\mathrm{K}]^{+}\right)$ have large structure with $\Omega_{\mathrm{D}}$ of $215 \AA^{2}$ and $217 \AA^{2}$, respectively. The argentated $6 \alpha-\mathrm{OHP}$ ion $\left([6 \alpha-\mathrm{OHP}+\mathrm{Ag}]^{+}\right)$forms a conformer with an intermediate size $\left(\Omega_{\mathrm{D}} \sim 211 \AA^{2}\right)$.

\section{Gas-Phase Structures of Cationized PTX and Its Metabolites}

To understand the observed conformational change of PTX and its metabolites induced by attached cationic species, the $\Omega_{\mathrm{D}, \text { theo }}$ of PTX and its metabolite ions were evaluated using the DFT optimized structures. Figure 2 shows representative, energetically favored structures of PTX, $6 \alpha-\mathrm{OHP}$, and $3 p$-OHP ions, wherein the $\Omega_{\mathrm{D} \text {,theo }}$ values show good agreement with $\Omega_{\mathrm{D} \text {,exp. }} \Omega_{\mathrm{D} \text {,exp }}$ are listed and compared with the $\Omega_{\mathrm{D} \text {,theo }}$ in Table 1. See Supplementary Figure S2 for additional DFT optimized structures and Supplementary Figures S3-S5 for scatter plots of $\Omega_{\mathrm{D} \text {,theo }}$ versus potential energies. For protonated PTX ions, the $\Omega_{\mathrm{D} \text {,theo }}$ values of both energetically stable P1 and P2 structures (Figure 2a and b) show good agreement with $\Omega_{\mathrm{D}, \exp }$ value of the larger conformer $\left(\sim 212 \AA^{2}\right)$. In the P1 structure, the proton binds to the $2^{\circ}$ amine group (N5), and forms an intramolecular hydrogen bond with the adjacent carbonyl group (O7). In the P2 structure, the protonated carbonyl group (O4) does not form an intramolecular hydrogen bond with adjacent atoms. Nevertheless, the protonation of the carbonyl oxygen $\mathrm{O} 4$ is favored because of the charge delocalization through the adjacent phenyl (Ph1) and amine (N4) groups (Supplementary Scheme S1). The $\Omega_{\mathrm{D} \text {,theo }}$ values calculated for A and B structures (Figure 2c and d) show good agreement with $\Omega_{\mathrm{D} \text {,exp }}$ value of the small conformer $\left(\sim 204 \AA^{2}\right)$. DFT-based calculations show that the A and B structures are energetically stable in the case of $[\mathrm{PTX}+\mathrm{H}]^{+}$.
In the A structure, protonation occurs at the carbonyl oxygen, O18 (see Figure 2 for labels), whereas a hydrogen bond is formed with a neighboring hydroxyl group, O15. For the B structures, the hydrogen bonding network is formed between the protonated $\mathrm{O} 4$ and $\mathrm{O} 12$.
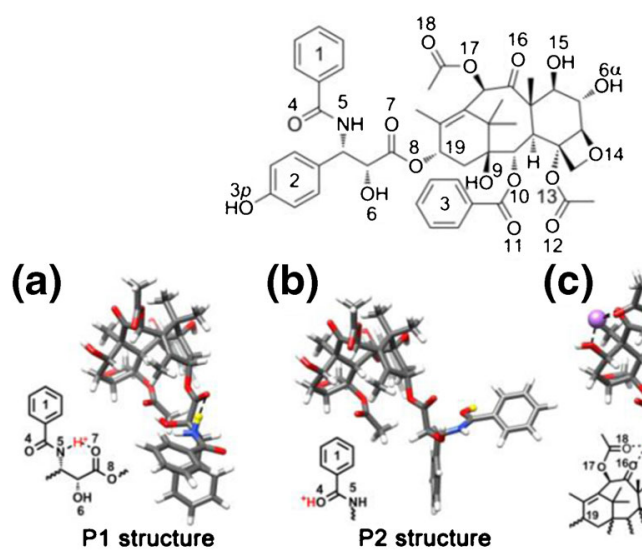

(b)

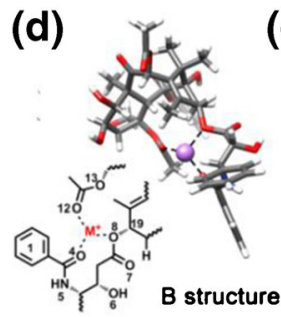

(e)

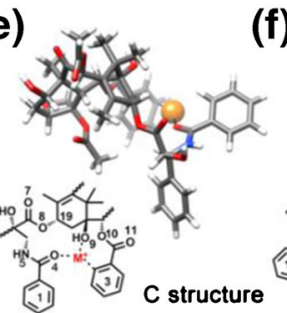

(c)

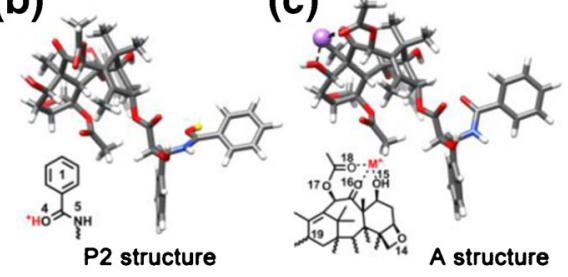

(f)

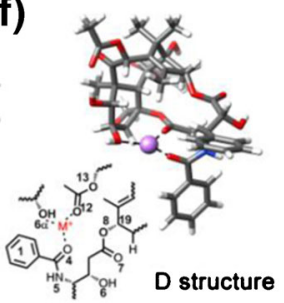

Figure 2. Representative structures from DFT calculations. Potential interactions between electron donors, such as oxygen atoms and phenyl groups, and the nearby cations are indicated with dashed lines; representative (a) P1 and (b) P2 structures from $[\mathrm{PTX}+\mathrm{H} \text { (yellow sphere) }]^{+}$, (c) A, (d) B structure from [PTX+ $\mathrm{Li}$ (purple sphere) $]^{+}$, (e) C structure from [PTX + Ag (orange sphere) $]^{+}$, and (f) D structure from $[6 \alpha-O H P+L i]^{+}$. The rest of the structures are shown in Supplementary Figure S2 
Table 1. Comparison of Experimental and Theoretical $\Omega_{\mathrm{D}}$ Values $\left(\AA^{2}\right)$. Standard Deviation $(\sigma)$ of Fitted Gaussian Curve is Noted with $\Omega_{\text {D.exp. Standard Deviation is }}$ also Noted with $\Omega_{\mathrm{D} \text {,theo }}$. Corresponding Structures are Listed with Bold Characters. See Supplementary Figure $\mathrm{S} 2$ for the Descriptions of E Structure

\begin{tabular}{|c|c|c|c|c|c|c|c|}
\hline & & \multicolumn{2}{|l|}{ PTX } & \multicolumn{2}{|l|}{$3 p-\mathrm{OHP}$} & \multicolumn{2}{|l|}{$6 \alpha-\mathrm{OHP}$} \\
\hline & & $\Omega_{\mathrm{D}, \exp }$ & $\Omega_{\mathrm{D} \text {,theo }}$ & $\Omega_{\mathrm{D}, \exp }$ & $\Omega_{\mathrm{D} \text {,theo }}$ & $\Omega_{\mathrm{D}, \exp }$ & $\Omega_{\mathrm{D} \text {,theo }}$ \\
\hline \multirow[t]{2}{*}{$\mathrm{H}^{+}$} & Compact & $204 \pm 3$ & $\begin{array}{l}207 \pm 2(\mathbf{A}) \\
207 \pm 1(\mathbf{B})\end{array}$ & $209 \pm 2$ & $\begin{array}{l}211 \pm 1(\mathbf{A}) \\
210 \pm 2(\mathbf{B})\end{array}$ & $205 \pm 3$ & $\begin{array}{l}208 \pm 1 \text { (A) } \\
204 \pm 1 \text { (D) }\end{array}$ \\
\hline & Extended & $212 \pm 4$ & $\begin{array}{l}212 \pm 1(\mathbf{P 1}) \\
211 \pm 1(\mathbf{P 2})\end{array}$ & $217 \pm 3$ & $\begin{array}{l}215 \pm 2(\mathbf{P 1}) \\
217 \pm 1(\mathbf{P 2})\end{array}$ & $213 \pm 3$ & $\begin{array}{l}213 \pm 1(\mathbf{P 1}) \\
212 \pm 1(\mathbf{P 2})\end{array}$ \\
\hline \multirow[t]{2}{*}{$\mathrm{Li}^{+}$} & $\begin{array}{l}\text { Fronting } \\
\text { Dominating }\end{array}$ & $\begin{array}{l}204 \pm 2 \\
211 \pm 3\end{array}$ & $\begin{array}{l}206 \pm 1(\mathbf{E}) \\
210 \pm 2(\mathbf{A}) \\
212 \pm 2(\mathbf{B})\end{array}$ & $\begin{array}{l}209 \pm 3 \\
216 \pm 3\end{array}$ & $\begin{array}{l}209 \pm 1(\mathbf{E}) \\
214 \pm 2(\mathbf{A}) \\
215 \pm 1(\mathbf{B})\end{array}$ & $\begin{array}{l}209 \pm 3 \\
213 \pm 2\end{array}$ & $\begin{array}{l}208 \pm 2(\mathbf{D}) \\
211 \pm 1(\mathbf{A}) \\
213 \pm 1(\mathbf{B})\end{array}$ \\
\hline & Tailing & - & - & - & - & $219 \pm 3$ & - \\
\hline \multirow[t]{2}{*}{$\mathrm{Na}^{+}$} & Fronting & - & - & - & - & $210 \pm 2$ & $208 \pm 2(\mathbf{D})$ \\
\hline & Dominating & $211 \pm 3$ & $\begin{array}{l}213 \pm 2(\mathbf{A}) \\
212 \pm 1(\mathbf{B})\end{array}$ & $216 \pm 3$ & $\begin{array}{l}216 \pm 2(\mathbf{A}) \\
214 \pm 1(\mathbf{B})\end{array}$ & $215 \pm 3$ & $\begin{array}{l}213 \pm 1(\mathbf{A}) \\
215 \pm 2(\mathbf{B})\end{array}$ \\
\hline \multirow[t]{2}{*}{$\mathrm{K}^{+}$} & Dominating & $212 \pm 3$ & $\begin{array}{l}212 \pm 1(\mathbf{B}) \\
211 \pm 1(\mathbf{E})\end{array}$ & $216 \pm 3$ & $215 \pm 1(\mathbf{B})$ & $217 \pm 3$ & $\begin{array}{l}219 \pm 1 \text { (A) } \\
214 \pm 2(\mathbf{D})\end{array}$ \\
\hline & Tailing & $218 \pm 4$ & $219 \pm 2(\mathbf{A})$ & $222 \pm 5$ & $222 \pm 1(\mathbf{A})$ & - & - \\
\hline $\mathrm{Ag}^{+}$ & Dominating & $204 \pm 3$ & $204 \pm 2(\mathbf{C})$ & $208 \pm 3$ & $207 \pm 2(\mathbf{C})$ & $211 \pm 3$ & $210 \pm 1(\mathbf{D})$ \\
\hline
\end{tabular}

Two energetically favored structures are typically observed for alkali metalated PTX ions (Figure $2 \mathrm{c}$ and $\mathrm{d}$ ). In the A structure (Figure 2c), the three oxygen atoms (O15, O16, and O18) interact with the alkali metal cations. In the B structure (Figure 2d), the metal cation is interacting with the $\mathrm{O} 4, \mathrm{O} 8$, and $\mathrm{O} 12$ atoms. Our theoretical analysis indicates that a A or B structure can be the dominating conformer for all alkali metalated PTX ions, except for $[\mathrm{PTX}+\mathrm{K}]^{+}$. In case of [PTX $+\mathrm{K}]^{+}$, the $\Omega_{\mathrm{D} \text {,theo }}$ of B structure is in more close agreement with the $\Omega_{\mathrm{D} \text {,exp }}$ of the dominating structure, whereas the $\Omega_{\mathrm{D} \text {,theo }}$ of A structure agrees with that of the tailing conformer.

The most compact metalated structure determined on the basis of our DFT calculations is the C structure (Figure 2e), wherein the metal cation interacts with the $\mathrm{Ph} 3, \mathrm{O} 4$, and $\mathrm{O} 9$ atoms. C structure is energetically favored in case of [PTX + $\mathrm{Ag}]^{+}$. In addition, $\Omega_{\mathrm{D} \text {,theo }}$ of $\mathrm{C}$ structure is close to $\Omega_{\mathrm{D} \text {,exp }}$, which explains the compactness of $[\mathrm{PTX}+\mathrm{Ag}]^{+}$in the IM distribution. Moreover, the $\mathrm{C}$ structure indicates that silver metal cation has a distinguishable cation $-\pi$ interaction compared with alkali metal cations. The silver metal cation is positioned at the periphery of the phenyl ring Ph3. However, the silver metal cation positioned at the periphery of the ring retains comparably strong interaction to that of the silver- $\pi$ interaction at the center of the ring [44]. Furthermore, X-ray crystal structures of related argentated ligands reveal that silver metal cations are bound at the periphery of the aromatic ring [45], as observed in the $\mathrm{C}$ structure.

IM spectra of cationized $3 p$-OHP show similar trends as those observed with PTX (Figure 1a and b). While cations tend to interact simultaneously with multiple electron-rich functional groups to maximize the binding energy, the long distance between the potential cation binding sites and the hydroxyl group at the $3 p$ position precludes potential ion-dipole interactions. As a consequence, DFT optimized structures of cationized $3 p$-OHP are generally consistent with those observed in the case of PTX while retaining marginally higher
$\Omega_{\mathrm{D} \text {,theo }}$ values owing to the hydroxyl group at the $3 p$ position (Supplementary Table S1).

Cationized $6 \alpha-\mathrm{OHP}$ have specific, energetically stable conformers classified as D structures (Figure 2f). In the protonated ions, the $\mathrm{O} 4$ and $\mathrm{O} 6 \alpha$ atoms are involved in hydrogen bonding. In case of the metalated ions, the $\mathrm{O} 4$, $\mathrm{O} 12$, and $\mathrm{O} 6 \alpha$ atoms interact with the attached metal cation. D structure shows relatively small $\Omega_{\mathrm{D} \text {, theo }}$ values for cationized $6 \alpha-\mathrm{OHP}$. The stability and compactness of D structure provides further support to the observation that the structures of $[6 \alpha-\mathrm{OHP}+\mathrm{Li}]^{+}$and $[6 \alpha-\mathrm{OHP}+\mathrm{Na}]^{+}$are relatively more compact when compared with those from PTX and $3 p$-OHP (Figure $1 \mathrm{c}$ ). $\Omega_{\mathrm{D} \text {, theo value of } \mathrm{D} \text { structure }}$ is also consistent with the $\Omega_{\mathrm{D}, \exp }$ in the $[6 \alpha-\mathrm{OHP}+\mathrm{Ag}]^{+}$.

\section{Collision Induced Dissociations of PTX and Its Metabolites}

PTX and its metabolites were investigated further using collision induced dissociation (CID) in an ultrahigh resolution mass spectrometer (Q-Orbitrap instrument). Figure 3 shows CID mass spectra of cationized PTX, $3 p-\mathrm{OHP}$, and $6 \alpha-\mathrm{OHP}$. The proposed structures of CID fragments are shown in Scheme 2 and listed in Supplementary Tables S2-S4.

The CID of $[\mathrm{PTX}+\mathrm{H}]^{+}$yields over 40 fragments (see the top panel, Figure 3a, and Supplementary Table S2). The fragment termed L ( $\mathrm{m} / \mathrm{z} 285)$, resulting from the dissociation of the ester bond O8-C 19 (see Figure 2 for the labeling of atoms), is the most abundant fragment (Scheme 2). The L subfragment product resulting from the loss of formic acid ( $-46 \mathrm{Da})$ is also observed at $\mathrm{m} / z 239$ (L1). The loss of $46 \mathrm{Da}$ can also be explained by the consecutive loss of $\mathrm{H}_{2} \mathrm{O}$ and $\mathrm{CO}$ [46]. The expected R fragment ( $m / z 568)$, resulting from the loss of neutral L fragment from PTX, is not observed in the CID mass spectra. However, R subfragment products from the dissociation of ester bonds as acetic acids ( $-60 \mathrm{Da}, \mathrm{AA}$ ) and/or as 
(a)

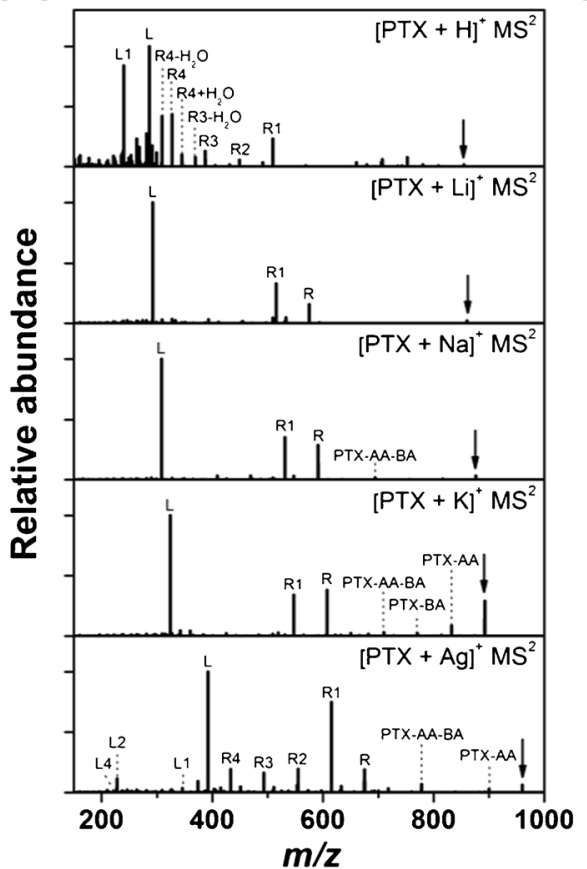

(b)

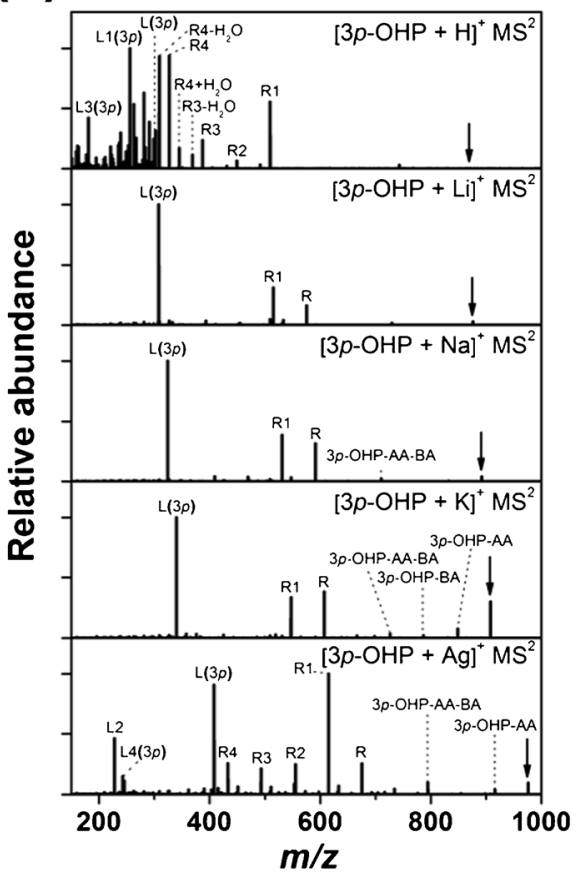

(c)

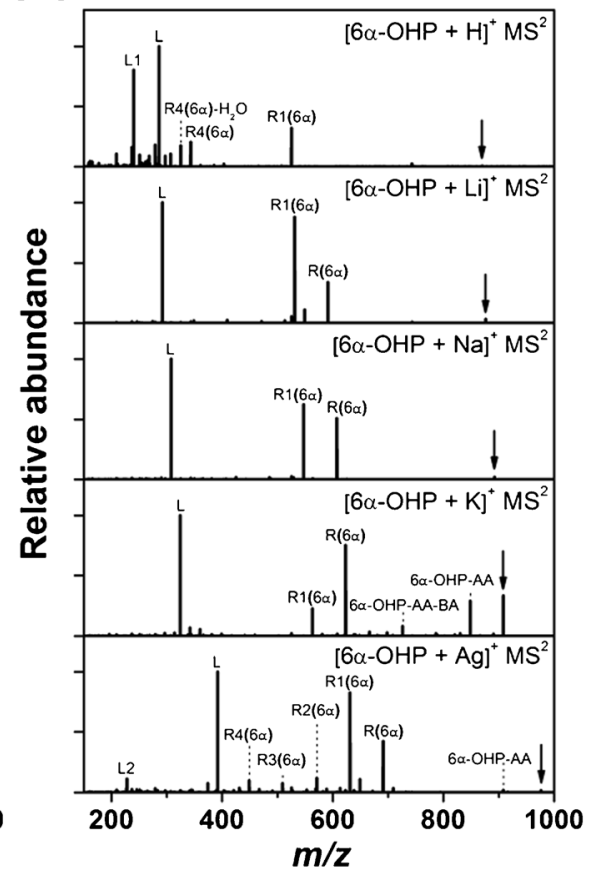

Figure 3. Tandem mass spectra of (a) PTX, (b) 3p-OHP, and (c) 6a-OHP ions. See Scheme 2 for the fragment structures and Supplementary Tables S2-S4 for the relative abundances with observed $m / z$ and exact mass. $L(3 p)$ is $L$ fragment of $3 p-O H P$, which is identical to $L$ fragment except for hydroxyl group at the para position of phenyl group, $P h 2$. $R(6 \alpha)$ is a $R$ fragment that has extra hydroxyl group at the $6 a$ position

benzoic acid (-122 Da, BA) are observed at $\mathrm{m} / \mathrm{z} 508$ (R1), 448 (R2), 386 (R3), and 326 (R4) (Scheme 2). Unidentified fragments were observed over the $\mathrm{m} / \mathrm{z}$ range between 150 and 350 . In the CID mass spectra of the metalated PTX ions, ester bond dissociation occurs selectively. L, R, and R1 fragments are observed as dominating fragments in the CID mass spectra of all alkali metalated PTX ions (Figure 3a). These fragments were observed in previous reports that studied PTX, also with similar trends in the abundances [19, 20]. The CID mass spectra of $[\mathrm{PTX}+\mathrm{Ag}]^{+}$also displays fragments resulting from the cleavage of ester bonds (R, R1, R2, R3, R4, and L). The phenyl group containing small fragments, L2 and L4, with $\mathrm{m} / \mathrm{z}$ 121 and 120, respectively, is particularly observed. The presence of L2 and L4 is consistent with the predicted strong silver- $\pi$ interaction in $[\mathrm{PTX}+\mathrm{Ag}]^{+}$. Considering that silver $-\pi$ interaction is sustained during the low energy CID [37, 47],

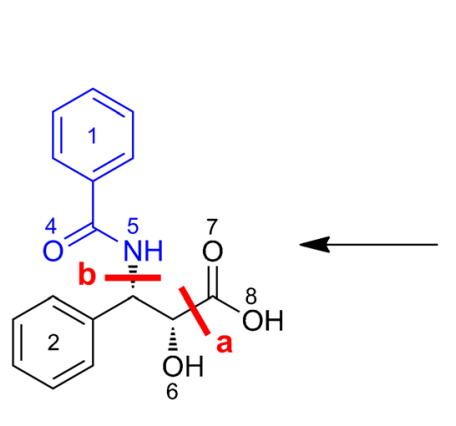

L, $285 \mathrm{Da}$

Dissociation site

$$
\text { a }
$$

b

b

$\mathrm{a}$ and $\mathrm{b}$

$\begin{array}{ll}\text { a } & \text { Subfragments } \\ \text { b } & \text { L1, 239 Da } \\ \text { b } & \text { L2, 121 Da } \\ \text { and b } & \text { L3, 164 Da } \\ \text { L4, 120 Da }\end{array}$

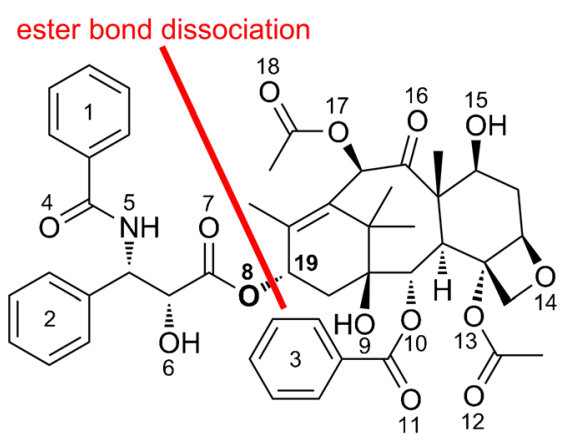

Paclitaxel (PTX)

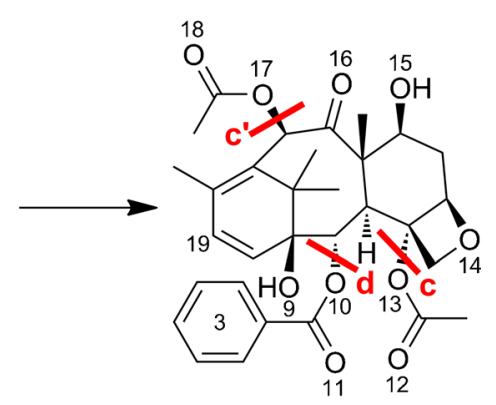

R, $568 \mathrm{Da}$

Dissociation site
c or $c^{\prime}$
$c$ and $c^{\prime}$
$c$ or $c^{\prime}, d$

$c, c^{\prime}$ and $d$
Subfragments

R1, $508 \mathrm{Da}$

R2, 448 Da

R3, $386 \mathrm{Da}$

R4, 326 Da

Scheme 2. Proposed structures and molecular weights of $L$ and $R$ fragments and their subfragments, $L 1-L 4$ and $R 1-R 4$, respectively 
silver $-\pi$ interaction may play a potential role in the fragmentation pathway as observed with L2 and L4.

The dissociation patterns observed in the CID mass spectra of alkali metalated $3 p$-OHP ions show almost identical patterns compared with those of alkali metalated PTX ions (Figure 3b, Supplementary Table S3). On the other hand, the CID mass spectra of cationized $6 \alpha-\mathrm{OHP}$ display patterns that are different from those of PTX and 3p-OHP (Figure 3c, Supplementary Table S4). Fewer fragments are observed in the $\mathrm{m} / \mathrm{z}$ range 150 to 350 for protonated $6 \alpha-\mathrm{OHP}$ ions. The relative abundances of the $\mathrm{R}$ and R1 fragments are higher for alkali metalated $6 \alpha-\mathrm{OHP}$ ions.

Series of IM-CID-MS (Supplementary Figure S6) experiments were also performed at the transfer of the Synapt G2 HDMS instrument, and the results have shown good agreement with those acquired from the Q-Orbitrap instrument (Figure 3). The calculated ratios between the sum of $\mathrm{L}$ fragment and its subfragments over those of $\mathrm{R}$ fragments are similar to those obtained from the Q-Orbitrap instrument (L/R fragment ratio, Supplementary Figures S7 and S8), except for the lithiated ions. Multiple collisions during the CID process at the transfer cell may have caused the loss of L fragments for the lithiated ions. Nevertheless, the similarities between the two series of data indicate the generality of our experimental observations. However, relative abundances of the $\mathrm{L}$ fragments are notably reduced in the series of CID-IM-MS experiments (Supplementary Figures S9 and S10). The high energy of ions attained from acceleration at the trap cell may have caused the escape of the $\mathrm{L}$ fragments from the confinement of the TW ion guide, during the IM separation.

The ester bond dissociation in the gas phase occurs via thermal ester elimination reaction (Scheme 3) [48, 49]. The ester bond is cleaved when the carbonyl oxygen of the ester group donates electrons to $\beta$-hydrogen and the ether oxygen withdraws electrons from the $\mathrm{C} \alpha$ [49]. Also, ester bond dissociation can occur by ether oxygens, which donate electrons to $\mathrm{C} \beta$, and carbonyl oxygens, which withdraw electrons from $\beta$ hydrogen (Scheme 3) [36]. It is known that a charge withdrawing/donating group attached to $\mathrm{C} \alpha$ or $\mathrm{C} \beta$ affects the rate of ester elimination reaction [49]. Thus, we suggest that ion-dipole interaction between cation and either of the ester oxygen atoms $\mathrm{O} 7$ or $\mathrm{O} 8$ stabilizes the $\mathrm{L} / \mathrm{R}$ fragmentation reaction intermediate by enhancing electron withdrawing power of an ester oxygen atom.

The B structure on Figure 2d, which corresponds to the dominant conformers of the overall alkali metalated PTX ions, displays the metal cations interacting with the $\mathrm{O} 4, \mathrm{O} 8$, and $\mathrm{O} 12$ atoms. The alkali metal cations, bound to the ester group oxygen (O8), facilitate the charge-induced fragmentation (Scheme 4a) [36]. Interactions between alkali metal cations and the $\mathrm{O} 4$ and O8 result in a high abundance of $\mathrm{L}$ fragment from the CID of the alkali metalated PTX ions (Figure 3a, Supplementary Figure S7). Interaction of alkali metal cation with the carbonyl oxygen $\mathrm{O} 12$ is responsible for the formation of $\mathrm{R}$ fragment. In addition, abundant $\mathrm{R} 1$ might be attributed to the fragmentation of AA, by stabilizing the intermediate in the dissociation reaction of the acetate ester, through the ion-dipole interaction between alkali metal cations and the carbonyl oxygen O12. This

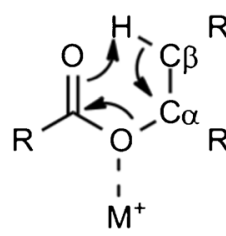

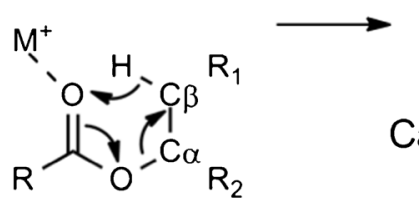<smiles>[R][R]([R2])=C[O-]</smiles>

Carboxylic acid Alkene

\section{Ester}

Scheme 3. Simplified scheme for the ester bond dissociation mechanism

explains the presence of $\mathrm{R} 1$ fragment along with $\mathrm{R}$ fragment in CID mass spectra of all alkali metalated ions in Figure 3a.

Since the hydroxyl group at the $3 p$ position is not directly involved in the interaction with metal cations (Supplementary Table S1), the CID mass spectra of alkali metalated ions of $3 p$ OHP ions show almost identical dissociation patterns to those of PTX. In contrast to $3 p$-OHP, IM measurements and the DFT calculations indicate that the metal cation interacts with the $\mathrm{O} 4$, O12, and O6 $\alpha$ atoms in $6 \alpha$-OHP (see D structure, Figure 2f). Although the metal cation does not interact with the ester group (O7 and $\mathrm{O} 8)$, the ester bond is selectively dissociated, as
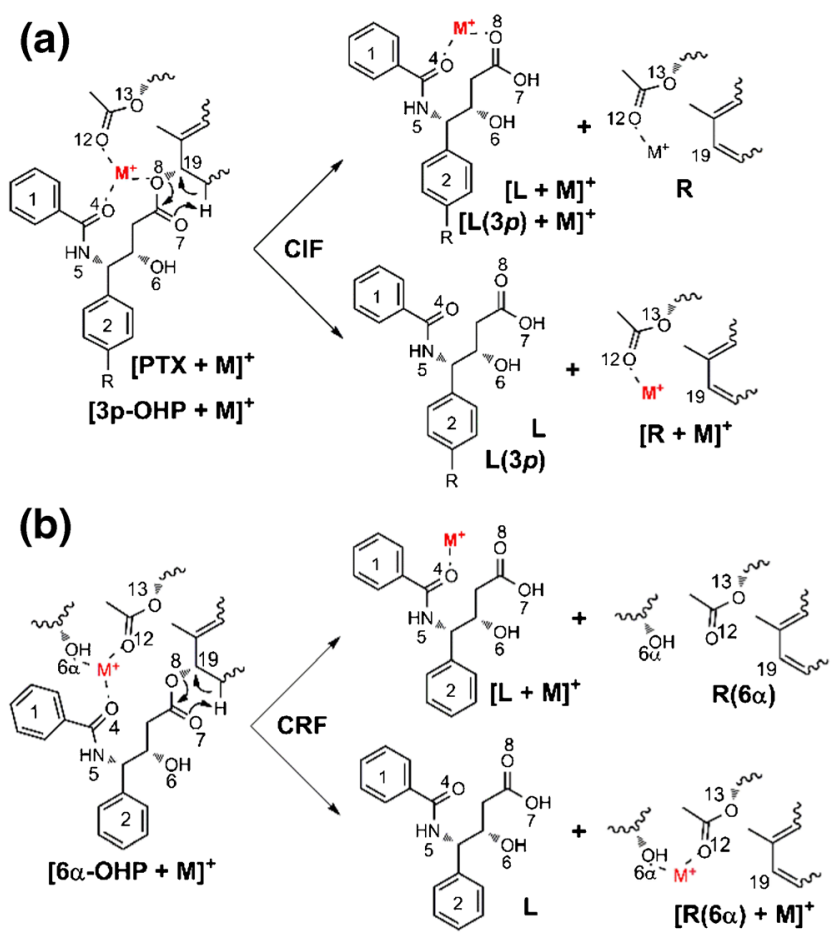

Scheme 4. Simplified scheme for (a) charge-induced ester bond dissociation reaction (CIF) initiated from alkali metal cations in B structure. Two L type oxygen atoms (O4 and 08$)$ and one $\mathrm{R}$ type oxygen atom $(\mathrm{O} 12)$ interact with the metal cation in PTX and 3p-OHP. (b) Charge remote fragmentation (CRF) via D structure shows two R type oxygen atoms $(\mathrm{O12}, \mathrm{O} 6 \mathrm{a})$ and one $\mathrm{L}$ type oxygen atom $(\mathrm{O} 4)$ are binding with metal cation in $6 \mathrm{a}-\mathrm{OHP}$ 
indicated by the CID mass spectra of the alkali metalated $6 \alpha-$ OHP ions (Figure 3c). We infer that these dissociations occur via charge-remote fragmentation, a dissociation process that is independent of the charge state and charge binding site (Scheme 4b) [50]. As thermal ester elimination reaction occurs without cations near ester oxygen atoms in the gas phase, the previously reported mechanism [49] for this reaction is likely to be the mechanism of the charge-remote ester bond dissociation. Interaction of the metal cation with the $\mathrm{O} 12$ and $\mathrm{O} 6 \alpha$ increases the probability of localizing the charge-carrying metal cation to $\mathrm{R}$ fragment after ester bond dissociation by CID. Yet, L fragment is still abundant from the CID mass spectra of the alkali metalated $6 \alpha-\mathrm{OHP}$ ions because of the charge delocalization at benzamide O4 (Supplementary Scheme S1).

Again, DFT calculations were performed to address the energetic comparisons between the metalation of $\mathrm{L}$ and $\mathrm{R}$ fragments. Since the addition of cations introduces additional vibrational modes, transition state structures with the cations can only be calculated with reasonable computational cost when the molecule is small and its potential cation binding sites are not spread over the molecule [34, 37]. PTX is too large (854 Da), and its potential cation binding sites are spread over the molecule. For this reason, we calculated the final structure and the energies of $\mathrm{L}$ and $\mathrm{R}$ fragment ions with the metal cations. Calculated energetics for the ester bond dissociation is shown in Figure 4 with DFT optimized geometries. As seen in Figure $4 \mathrm{a}$, the overall $\mathrm{L} / \mathrm{R}$ dissociation reaction is endothermic by $\sim 60-80 \mathrm{~kJ} / \mathrm{mol}$. The binding of the metal cation to the $\mathrm{O} 4$ and $\mathrm{O} 8$ atoms in the $\mathrm{L}$ fragments of PTX, $3 p$-OHP, and $6 \alpha-\mathrm{OHP}$ is energetically most favored to all metal cations investigated in this study $\left(\mathrm{L}_{4,8}\right.$ structure, Figure $\left.4 \mathrm{~b}\right)$. The second most favored binding sites are $\mathrm{Ph} 2$ and $\mathrm{O} 4\left(\mathrm{~L}_{2,4}\right.$ structure, Figure $4 \mathrm{c})$. The energy gap between the two structures is $\sim 20-50 \mathrm{~kJ} / \mathrm{mol}$ for alkali metalated L fragment ions (Supplementary Table S5). However, in the case of the argentated molecules, the difference in the energies of $\mathrm{L}_{4,8}$ and $\mathrm{L}_{2,4}$ structures is negligible [B3LYP/LANL2DZ-6-31G(d), Supplementary Table S5], indicating that the strong silver- $\pi$ interaction can influence fragmentation pathways. Interaction of the metal cations with the $\mathrm{O} 15$, O16, and $\mathrm{O} 18\left(\mathrm{R}_{15,16,18}\right.$ structure, Figure $\left.4 \mathrm{~d}\right)$ in the $\mathrm{R}$ fragments is favored over the interactions with the $\mathrm{O} 12$ and $\mathrm{O} 14$ $\left(\mathrm{R}_{12,14}\right.$ structure Figure $4 \mathrm{e}$ ) by $\sim 35-70 \mathrm{~kJ} / \mathrm{mol}$ (Supplementary Table S6) for the all metalated PTX $3 p-\mathrm{OHP}$, and $6 \alpha-\mathrm{OHP}$ ions.

The energetic comparisons reveal that metalation of the

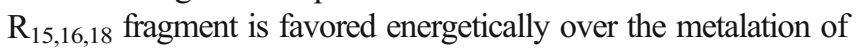
the $\mathrm{L}_{4,8}$ fragment by $\sim 20-40 \mathrm{~kJ} / \mathrm{mol}$ (Supplementary Table S7). However, the sum of $\mathrm{L}$ fragment and its subfragments is higher than that of R type products for alkali metalated PTX and $3 p$-OHP ions (Figure 3a and b, Supplementary Figure S7). Only in the CID mass spectra of alkali metalated $6 \alpha-\mathrm{OHP}$ ions, the sum of $\mathrm{L}$ fragments to that of $\mathrm{R}$ fragments are comparable (Figure 3c, Supplementary Figure S7). Metal cations prefer to interact with the $\mathrm{O} 12$ atom in the $\mathrm{B}$ and D structures (Figure 2), which are energetically favored in PTX and its metabolites before the CID. Thus, it is inferred that metal cations are kinetically trapped by the $\mathrm{O} 12$ atom of the $\mathrm{R}$ fragment, along with the $\mathrm{O} 4$ and $\mathrm{O} 8$ atoms in the $\mathrm{L}$ fragment, during the ester bond dissociation via chargeinduced fragmentation for the PTX and $3 p$-OHP. The dissociation of ester bonds from metalated $6 \alpha-\mathrm{OHP}$ seem to occur via chargeremote fragmentation in the $\mathrm{D}$ structure where metal cation is interacting with two oxygen atoms (O12 and $\mathrm{O} 6 \alpha$ ) prior to the CID. As a result, metalated L fragments are observed with high relative abundances during CID of PTX and $3 p$-OHP ions for the metal interaction with the $\mathrm{O} 4$ and $\mathrm{O} 8$ atoms in $\mathrm{B}$ structure (Figure 3a and 7b, Supplementary Figure S7). The comparable
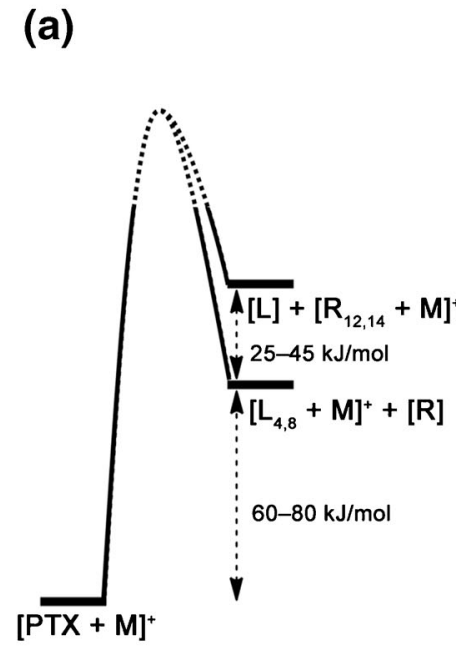

(b)

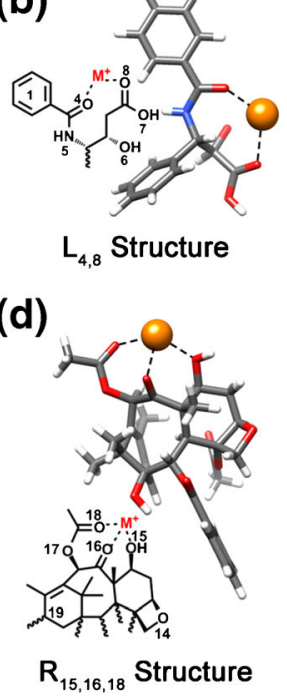

(c)

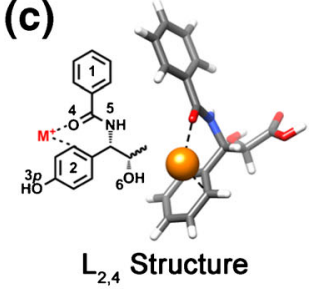

(e)

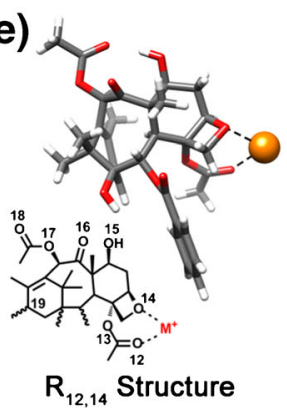

Figure 4. (a) Simplified reaction coordinate diagram of $L / R$ fragmentation. The reaction is endothermic by $60-80 \mathrm{~kJ} / \mathrm{mol}$. Further energetic details of the L/R fragment structures are listed in Supplementary Tables S6-S8. The dotted segment of the curve represents the undetermined transition state and activation energy. Nevertheless, calculated trends in energetic difference between $[\mathrm{L} 4,8+\mathrm{M}]^{+}+[\mathrm{R}]$ and $[\mathrm{R} 12,14+\mathrm{M}]^{+}+[\mathrm{L}]$ support observed L/R fragment ratios from PTX and its metabolites. (b) 2D and 3D structures of $L_{4,8}$ fragment, which is the most energetically favored structure. (c) $2 D$ and $3 D$ structures of second most favored $L$ fragment structure, $L_{2,4}$. 2D and 3D structures of (d) $R_{15,16,18}$ fragments and (e) $R_{12,14}$ fragments are also displayed 
relative abundances of the $\mathrm{L}$ fragments and $\mathrm{R}$ fragments from the CID mass spectra of metalated $6 \alpha-\mathrm{OHP}$ can be explained by the metal cation interaction with $\mathrm{O} 12$ and $\mathrm{O} 6 \alpha$ atoms in D structure (Scheme 4b). Further support is provided by DFT calculations, which shows that the smaller energy differences between the metalation of $\mathrm{L}_{4,8}$ and $\mathrm{R}_{12,14}$ fragments in $6 \alpha$-OHP ions compared with those of PTX and 3p-OHP ions (Supplementary Table S8).

\section{Conclusion}

Gas-phase structures and dissociation patterns of cationized PTX and its two major CYP metabolites, $3 p$-OHP and $6 \alpha$ OHP, were investigated using ESI-IM-MS, CID, and DFT calculations. Results from the IM-MS and DFT studies indicate that the hydroxyl substituent position significantly influences interactions between the metabolites and monovalent cations, leading to distinct gas-phase conformations for $3 p-\mathrm{OHP}$ and $6 \alpha-\mathrm{OHP}$. All metal cations investigated in this study selectively dissociate the ester bonds of PTX and its metabolites by CID. The presence of the hydroxyl group at the $6 \alpha$ positions plays an essential role in the interaction of $6 \alpha$-OHP with cations, resulting in conformations and dissociation patterns distinct from those exhibited by PTX and $3 p$-OHP.

In this study, we demonstrated the utility of IM-MS and theoretical calculations on understanding the structures and the fragment formation process of PTX and its metabolites. IMMS is a powerful tool that offers valuable insights into the structural dynamics of isomeric drug metabolites in the gas phase. Utilizing IM-MS analysis, a correlation between the CID pathways and gas-phase structures was established for PTX and its two hydroxylated isomers, especially in relation to metalation.

\section{Acknowledgments}

The authors acknowledge support for this work by a grant of the Korea Health Technology R\&D Project through the Korea Health Industry Development Institute (KHIDI), funded by the Ministry of Health and Welfare of Korea (grant no. HT13C0011-040013), and Basic Science Research Program through the National Research Foundation of Korea (NRF) funded by the Ministry of Education (no. 20120020209).

\section{References}

1. Sandler, A., Gray, R., Perry, M.C., Brahmer, J., Schiller, J.H., Dowlati, A., Lilenbaum, R., Johnson, D.H.: Paclitaxel-Carboplatin alone or with Bevacizumab for non-small-cell lung cancer. N. Engl. J. Med. 355, 2542-2550 (2006)

2. Miller, K., Wang, M., Gralow, J., Dickler, M., Cobleigh, M., Perez, E.A., Shenkier, T., Cella, D., Davidson, N.E.: Paclitaxel plus Bevacizumab versus Paclitaxel alone for metastatic breast cancer. N. Engl. J. Med. 357, 2666-2676 (2007)

3. Armstrong, D.K., Bundy, B., Wenzel, L., Huang, H.Q., Baergen, R., Lele, S., Copeland, L.J., Walker, J.L., Burger, R.A.: Intraperitoneal Cisplatin and Paclitaxel in ovarian cancer. N. Engl. J. Med. 354, 34-43 (2006)

4. Vermorken, J.B., Remenar, E., van Herpen, C., Gorlia, T., Mesia, R., Degardin, M., Stewart, J.S., Jelic, S., Betka, J., Preiss, J.H., van den Weyngaert, D., Awada, A., Cupissol, D., Kienzer, H.R., Rey, A.,
Desaunois, I., Bernier, J., Lefebvre, J.-L.: Cisplatin, Fluorouracil, and Docetaxel in unresectable head and neck cancer. N. Engl. J. Med. 357, 1695-1704 (2007)

5. Jordan, M.A., Wilson, L.: Microtubules as a target for anticancer drugs. Nat. Rev. Cancer 4, 253-265 (2004)

6. McGrogan, B.T., Gilmartin, B., Carney, D.N., McCann, A.: Taxanes, microtubules, and chemoresistant breast cancer. BBA-Rev. Cancer $\mathbf{1 7 8 5}$, 96-132 (2008)

7. Stordal, B., Pavlakis, N., Davey, R.: A systematic review of platinum and taxane resistance from bench to clinic: an inverse relationship. Cancer Treat. Rev. 33, 688-703 (2007)

8. García-Martín, E., Pizarro, R.M., Martínez, C., Gutierrez-Martín, Y., Pérez, G., Jover, R., Agúndez, J.A.G.: Acquired resistance to the anticancer drug paclitaxel is associated with induction of cytochrome P450 $2 \mathrm{C} 8$. Pharmacogenomics 7, 575-585 (2006)

9. Chun, Y.-J., Lee, S., Ae Yang, S., Park, S., Young Kim, M.: Modulation of CYP3A4 expression by ceramide in human colon carcinoma HT-29 cells. Biochem. Biophys. Res. Commun. 298, 687-692 (2002)

10. Nallani, S.C., Goodwin, B., Buckley, A.R., Buckley, D.J., Desai, P.B.: Differences in the induction of cytochrome P450 3A4 by taxane anticancer drugs, docetaxel and paclitaxel, assessed employing primary human hepatocytes. Cancer Chemother. Pharmacol. 54, 219-229 (2004)

11. Lewis, D.F.V.: Human cytochromes P450 associated with the phase 1 metabolism of drugs and other xenobiotics: a compilation of substrates and inhibitors of the CYP1, CYP2, and CYP3 families. Curr. Med. Chem. 10, 1955-1972 (2003)

12. Sergentanis, T., Economopoulos, K.: Four polymorphisms in cytochrome P450 1A1 (CYP1A1) gene and breast cancer risk: a meta-analysis. Breast Cancer Res. Treat. 122, 459-469 (2010)

13. Guengerich, F.P.: Cytochrome P450 and chemical toxicology. Chem. Res. Toxicol. 21, 70-83 (2007)

14. Václavíková, R., Horský, S., Šimek, P., Gut, I.: Paclitaxel metabolism in rat and human liver microsomes is inhibited by phenolic antioxidants. Naunyn Schmiedeberg's Arch. Pharmacol. 368, 200-209 (2003)

15. Vaclavikova, R., Soucek, P., Svobodova, L., Anzenbacher, P., Simek, P., Guengerich, F.P., Gut, I.: Diffrent in vitro metabolism of paclitaxel and docetaxel in humans, rats, pigs, and minipigs. Drug Metab. Dispos. 32, 666-674 (2004)

16. Oshiro, C., Marsh, S., McLeod, H., Carrillo, M.W., Klein, T., Altman, R.: Taxane pathway. Pharmacogenet. Genomics 19, 979-983 (2009)

17. Rochat, B.: Role of cytochrome P450 activity in the fate of anticancer agents and in drug resistance. Clin. Pharmacokinet. 44, 349-366 (2005)

18. Guo, W., Johnson, J.L., Khan, S., Ahmad, A., Ahmad, I.: Paclitaxel quantification in mouse plasma and tissues containing liposomeentrapped paclitaxel by liquid chromatography-tandem mass spectrometry: application to a pharmacokinetics study. Anal. Biochem. 336, 213-220 (2005)

19. Zhang, W., Dutschman, G.E., Li, X., Cheng, Y.-C.: Quantitation of paclitaxel and its two major metabolites using a liquid chromatographyelectrospray ionization tandem mass spectrometry. J. Chromatogr. B 879, 2018-2022 (2011)

20. Fernández-Peralbo, M.A., Priego-Capote, F., Luque de Castro, M.D., Casado-Adam, A., Arjona-Sánchez, A., Muñoz-Casares, F.C.: LC-MS/ MS quantitative analysis of paclitaxel and its major metabolites in serum, plasma and tissue from women with ovarian cancer after intraperitoneal chemotherapy. J. Pharm. Biomed. Anal. 91, 131-137 (2014)

21. Campuzano, I., Bush, M.F., Robinson, C.V., Beaumont, C., Richardson, K., Kim, H., Kim, H.I.: Structural characterization of drug-like compounds by ion mobility mass spectrometry: comparison of theoretical and experimentally derived nitrogen collision cross sections. Anal. Chem. 84, 1026$1033(2011)$

22. Williams, J.P., Bugarcic, T., Habtemariam, A., Giles, K., Campuzano, I., Rodger, P.M., Sadler, P.J.: Isomer separation and gas-phase configurations of organoruthenium anticancer complexes: ion mobility mass spectrometry and modeling. J. Am. Soc. Mass Spectrom. 20, 1119-1122 (2009)

23. Wu, C., Siems, W.F., Klasmeier, J., Hill, H.H.: Separation of isomeric peptides using electrospray ionization/high-resolution ion mobility spectrometry. Anal. Chem. 72, 391-395 (1999)

24. Shvartsburg, A.A., Creese, A.J., Smith, R.D., Cooper, H.J.: Separation of a set of peptide sequence isomers using differential ion mobility spectrometry. Anal. Chem. 83, 6918-6923 (2011)

25. Clemmer, D.E., Hudgins, R.R., Jarrold, M.F.: Naked protein conformations: cytochrome $c$ in the gas phase. J. Am. Chem. Soc. 117, 10141-10142 (1995) 
26. Hoskins, J.N., Trimpin, S., Grayson, S.M.: Architectural differentiation of linear and cyclic polymeric isomers by ion mobility spectrometry-mass spectrometry. Macromolecules 44, 6915-6918 (2011)

27. O'Donnell, R.M., Sun, X., Harrington, P.D.B.: Pharmaceutical applications of ion mobility spectrometry. TrAC Trends Anal. Chem. 27, 44-53 (2008)

28. Lanucara, F., Holman, S.W., Gray, C.J., Eyers, C.E.: The power of ion mobility-mass spectrometry for structural characterization and the study of conformational dynamics. Nat. Chem. 6, 281-294 (2014)

29. Bataglion, G.A., Souza, G.H.M.F., Heerdt, G., Morgon, N.H., Dutra, J.D.L., Freire, R.O., Eberlin, M.N., Tata, A.: Separation of glycosidic catiomers by TWIM-MS using $\mathrm{CO}_{2}$ as a drift gas. J. Mass Spectrom. 50, 336-343 (2015)

30. Domalain, V., Tognetti, V., Hubert-Roux, M., Lange, C., Joubert, L., Baudoux, J., Rouden, J., Afonso, C.: Role of cationization and multimers formation for diastereomers differentiation by ion mobility-mass spectrometry. J. Am. Soc. Mass Spectrom. 24, 1437-1445 (2013)

31. Gaucher, S.P., Leary, J.A.: Influence of metal ion and coordination geometry on the gas phase dissociation and stereochemical differentiation of $\mathrm{N}$ glycosides. Int. J. Mass Spectrom. 197, 139-148 (2000)

32. Seo, Y., Schenauer, M.R., Leary, J.A.: Biologically relevant metal-cation binding induces conformational changes in heparin oligosaccharides as measured by ion mobility mass spectrometry. Int. J. Mass Spectrom. 303, 191-198 (2011)

33. Duan, X., Luo, G., Chen, Y., Kong, X.: Effects of alkali metal ion cationization on fragmentation pathways of triazole-epothilone. J. Am. Soc. Mass Spectrom. 23, 1126-1134 (2012)

34. Grossert, J.S., Herrera, L., Ramaley, L., Melanson, J.: Studying the chemistry of cationized triacylglycerols using electrospray ionization mass spectrometry and density functional theory computations. J. Am. Soc. Mass Spectrom. 25, 1421-1440 (2014)

35. Wei, J., Bristow, A.T., O'Connor, P.: The competitive influence of $\mathrm{Li}^{+}$, $\mathrm{Na}+, \mathrm{K}+, \mathrm{Ag}+$, and $\mathrm{H}+$ on the fragmentation of a PEGylated polymeric excipient. J. Am. Soc. Mass Spectrom. 26, 166-173 (2015)

36. Chai, Y., Pan, Y.: The effect of cation size $(\mathrm{H}+, \mathrm{Li}+, \mathrm{Na}+$, and $\mathrm{K}+)$ on McLafferty-type rearrangement of even-electron ions in mass spectrometry. Sci. China Chem. 57, 662-668 (2014)

37. Shoeib, T., Cunje, A., Hopkinson, A.C., Siu, K.W.M.: Gas-phase fragmentation of the Ag+- phenylalanine complex: cation $-\pi$ interactions and radical cation formation. J. Am. Soc. Mass Spectrom. 13, 408-416 (2002)

38. Thalassinos, K., Grabenauer, M., Slade, S.E., Hilton, G.R., Bowers, M.T., Scrivens, J.H.: Characterization of phosphorylated peptides using traveling wave-based and drift cell ion mobility mass spectrometry. Anal. Chem. 81, 248-254 (2009)

39. Valentine, S., Counterman, A., Clemmer, D.: A database of 660 peptide ion cross sections: use of intrinsic size parameters for bona fide predictions of cross sections. J. Am. Soc. Mass Spectrom. 10, 1188-1211 (1999)

40. Wyttenbach, T., Helden, G.V., Batka Jr., J.J., Carlat, D., Bowers, M.T.: Effect of the long-range potential on ion mobility measurements. J. Am. Soc. Mass Spectrom. 8, 275-282 (1997)

41. Kim, K., Lee, J., Chang, T., Kim, H.: Characterization of polylactides with different stereoregularity using electrospray ionization ion mobility mass spectrometry. J. Am. Soc. Mass Spectrom. 25, 1771-1779 (2014)

42. Bondi, A.: van der Waals volumes and radii. J. Phys. Chem. 68, 441-451 (1964)

43. Silva, I.M.P.E., Profirio, D.D.M., de Paiva, R.E.F., Lancellotti, M., Formiga, A.L.B., Corbi, P.P.: A silver complex with ibuprofen: synthesis, solid state characterization, DFT calculations, and antibacterial assays. J. Mol. Struct. 1049, 1-6 (2013)

44. Granatier, J., Lazar, P., Otyepka, M., Hobza, P.: The nature of the binding of $\mathrm{Au}, \mathrm{Ag}$, and $\mathrm{Pd}$ to benzene, coronene, and graphene: from benchmark $\operatorname{CCSD}(\mathrm{T})$ calculations to plane-wave DFT calculations. J. Chem. Theory Comput. 7, 3743-3755 (2011)

45. Lindeman, S.V., Rathore, R., Kochi, J.K.: Silver(I) complexation of (poly)aromatic ligands. Structural criteria for depth penetration into cisstilbenoid cavities. Inorg. Chem. 39, 5707-5716 (2000)

46. Rogalewicz, F., Hoppilliard, Y., Ohanessian, G.: Fragmentation mechanisms of $\alpha$-amino acids protonated under electrospray ionization: a collisional activation and ab initio theoretical study1. Int. J. Mass Spectrom. 195/196, 565-590 (2000)

47. Sun, H., Wang, L., Pan, Y.: Gas-phase arylmethyl transfer and cyclodeamination of argentinated $N$-arylmethyl-pyridin-2-ylmethanimine. J. Am. Soc. Mass Spectrom. 25, 169-175 (2014)

48. Ji, H., Li, L., Xu, X., Ham, S., Hammad, L.A., Birney, D.M.: Multiphoton infrared initiated thermal reactions of esters: pseudopericyclic eightcentered cis-elimination. J. Am. Chem. Soc. 131, 528-537 (2008)

49. Erickson, J.A., Kahn, S.D.: Theoretical studies of thermal syn elimination reactions. The relative rates of ethyl formate, ethyl xanthate, and ethyl phosphinate eliminations. J. Am. Chem. Soc. 116, 6271-6276 (1994)

50. Cheng, C., Gross, M.L.: Applications and mechanisms of charge-remote fragmentation. Mass Spectrom. Rev. 19, 398-420 (2000) 